\title{
Research of Wearable Textile Antennas for WBAN Applications
}

\author{
Tarannum U. Pathan, Rajneesh K. Karn
}

\begin{abstract}
The emergence of Wireless Body Area Networks (WBAN) in recent times has diverted the attention of most researchers towards the field of wearable antennas. The WBAN has enabled communication between different devices by placing them on human body. This work is a review which intends to disclose the recent developments in the area of wearable Textile antennas for WBAN. Further the use of different textile materials has been studied and their performances have been evaluated. The results show that use of textile materials have not only increased the efficiency but also they are very flexible and make the antenna suitable for on/off body applications such as medical and military. The properties of antennas inside human body, on human body and finally at some distance from the human body have been studied. It has been noted that as the distance between human body and antenna reduces, the properties of antenna such as efficiency, directivity and gain degrade more and more. Also the resonant frequency of antenna shifts from its original position which is a very big issue and needs to be rectified. For textile materials the shift in resonant frequency is not too much and also the degradation in other properties of antenna such as efficiency, directivity and gain are insignificant.
\end{abstract}

Index Terms-In-body, ISM, MIMO,SAR, Textile antennas, Wearable antennas, WBAN

\section{INTRODUCTION}

Wireless body area network (WBAN) technology has the potential to provide an unprecedented opportunity for ubiquitous real-time healthcare and fitness monitoring in ambulances, emergency rooms, operating theatres, postoperative recovery rooms, clinics, homes and even on the move; such that many diseases could be prevented through early detection and doctors could give patients efficient advice on improving their health [1]. In recent years, there has been increasing concern about the safety of WBAN systems, particularly wearable electronics ranging over a multitude of applications including medical, entertainment and military. The emergence of Body Area Networks (BAN) in recent times has increased the interest of most of the researchers in the field of wearable antennas. Due to its widespread popularity most of the research has been done to improve the efficiency and flexibility of the wearable antennas for in- body and on-body applications.

Wearable Antennas are those antennas which operate near the human body, so human body will absorb some of the radiated energy and hence efficiency of antenna will reduce [2]-[5].The wearable antennas installed on human body may

Revised Manuscript Received on 14 August, 2019.

Tarannum U. Pathan, Research Scholar, Department of E \& C, Madhyanchal Professional University, Bhopal, M.P, India (Email: pathan.tannu24@gmail.com)

Rajneesh K. Karn, Professor, Department of E \& C , Madhyanchal Professional University, Bhopal, M.P, India(Email: dr.rajneeshkarn@gmail.com) communicate with each other or with an external antenna This type of network is known as Body Area Network (BAN) [6]. In-body antennas are those which are inserted inside human body and it is mostly used for medical purpose [7], whereas On-body antennas are those which are installed on the top of human body.

The emergence of BAN shows that in future almost everyone will be a part of this network, therefore wearable antenna should be carefully designed to achieve all the required properties when placed in the vicinity of human body or off the body and inside the human body.

\section{WEARABLE TEXTILE ANTENNAS}

The miniaturized textile antenna is designed and demonstrated for ISM band applications at $2.4 \mathrm{GHz}$ [13]. The proposed antenna used Shieldit conducting material on a $0.7 \mathrm{~mm}$ thick denim substrate with a low dielectric constant of 1.7, and the textile antenna patch has been fed by a $50 \Omega$ micro strip line.
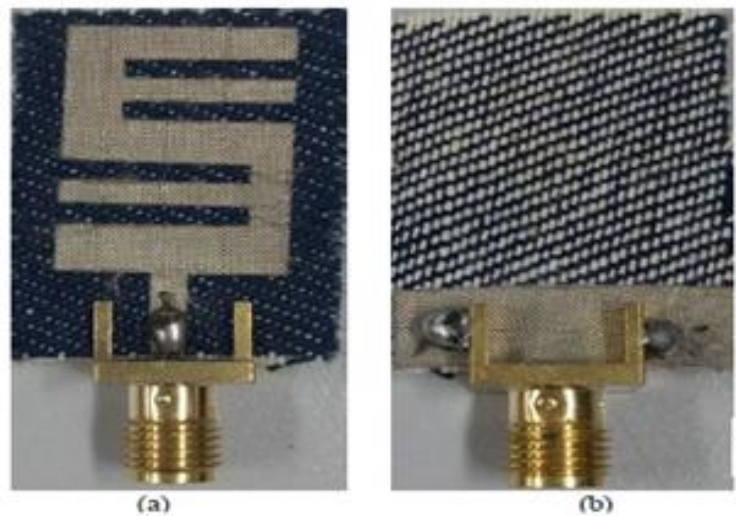

Fig 1. Prototype of the proposed antenna design (a) Front view (b) Back view [13]

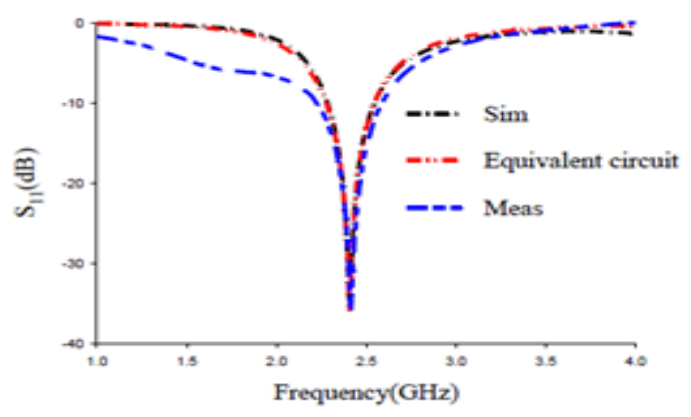

Fig 2. Simulated and measured reflection coefficient of proposed antenna [13] 
In Fig. 2, it is seen that the measured reflection coefficient has a wider bandwidth than the simulated one, which ranges from 2.23 to $2.59 \mathrm{GHz}$ with a bandwidth of $360 \mathrm{MHz}$ (15\%), while the simulated values range from 2.29 to 2.53 $\mathrm{GHz}$ with a bandwidth of $240 \mathrm{MHz}(10 \%)$. This may be due to the lossy properties of the substrate material itself.

\section{Bending Performance effect on Wearable antenna}

The investigation under bending conditions is experimentally studied along the vertical and horizontal bends as shown in Figure 3. The antenna are measured over polystyrene cylinders with dielectric constant $\mathrm{\varepsilon r} \approx 1$, using diameters (d) of $70 \mathrm{~mm}, 80 \mathrm{~mm}, 100 \mathrm{~mm}$, and $140 \mathrm{~mm}$. The differing diameters produce different antenna curvatures to test whether the operating frequency is sustained under bending condition, fulfilling the requirements for a reliable wearable antenna.

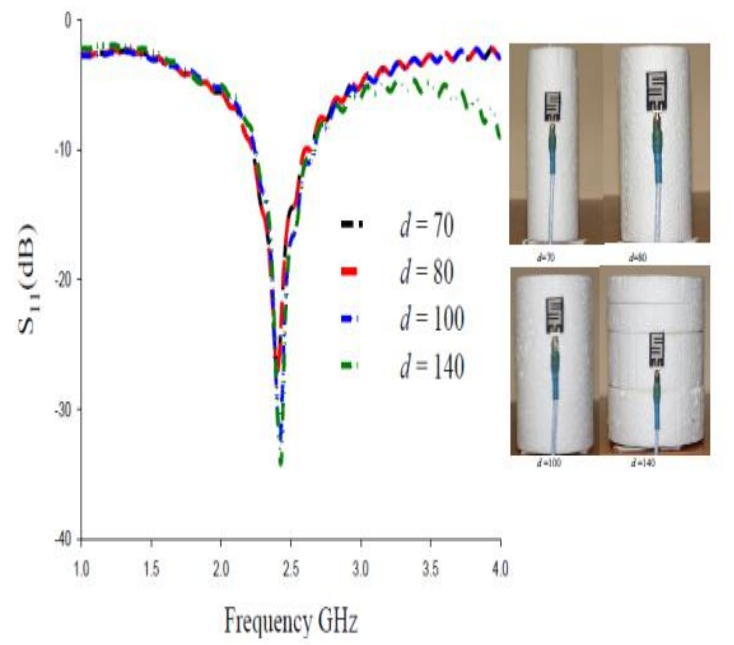

(a)

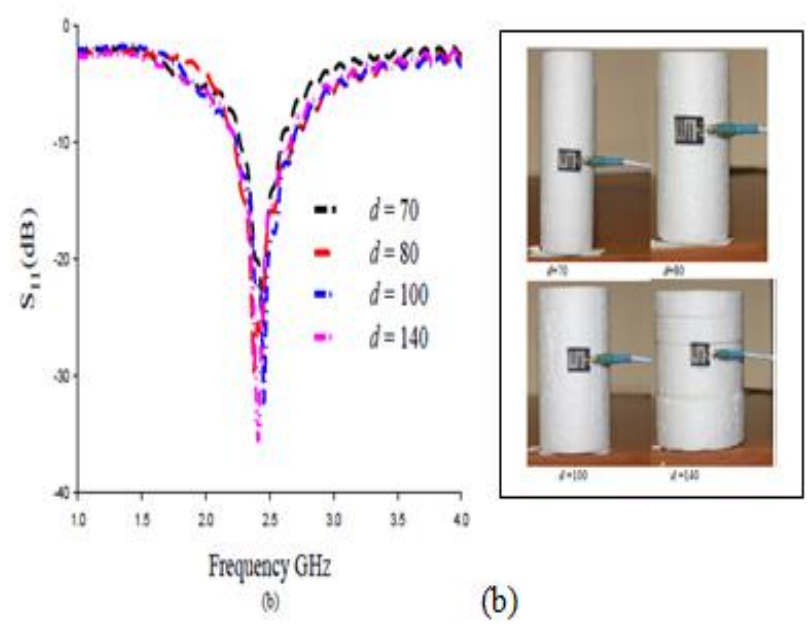

Fig 3. Measured reflection coefficient,S11 at the (a) $y$ axis, (b) $x$ - axis, for different bending diameters (in mm), respectively[13]

The measured reflection coefficient characteristics of vertical and horizontal bends are given in Fig.3. In this case, there is slight upward shift as the diameter is decreased. Fig. 3 (b) shows a $5 \mathrm{MHz}$ shift to higher frequency at $d=100$ $\mathrm{mm}$ for the horizontal case, which is negligible. Overall, even under bent condition, the antenna operates within the desired band without any appreciable frequency detuning.

\section{WEARABLE TEXTILE MIMO ANTENNA ON BODY FOR WBAN}

MIMO antenna has been designed according to the configuration in Fig. 4(a) with bending angle 40 deg and (b) antenna deformation $20 \mathrm{deg}$, with the final detailed geometries in [8]. Here, MIMO antenna occupies an area of $38.1 \mathrm{~mm} \times 38.1 \mathrm{~mm}$, with thickness of $2 \mathrm{~mm}$. It is implemented on a substrate with the permittivity of 1.2. [8]

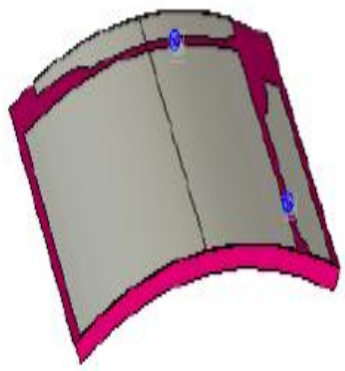

(a)

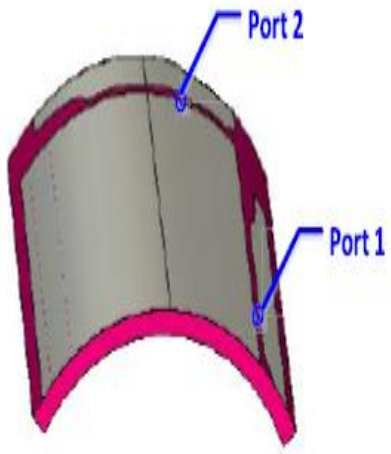

(b)
Fig 4. (a) Antenna deformation: $R x=40 \mathrm{~mm}$. (b) Antenna deformation: $R x=20 \mathrm{~mm}[8]$

In order to investigate the influence of the human body, the antenna is placed on the human arm, which is simulated as a four-layer cylinder, including skin, fat, muscle, and bone, as shown in the inset of Figure. 5. The thicknesses of the four layers are 2, 5, 20, and $13 \mathrm{~mm}$, respectively, with their material properties at $2.45 \mathrm{GHz}$ shown in Table II [6]. Fig. 7 shows the S-parameters of the antennas when fully attached on the arm. Compared with the S-parameters in Fig. 5,the centre frequency is detuned to the lower band by $250 \mathrm{MHz}$ due to high-permittivity loading, and the isolation is enhanced by $5 \mathrm{~dB}$ attributed to body loss. As the bandwidths of the antennas are large in free space, the antennas are still well matched from 2.4 to $2.5 \mathrm{GHz}$ after frequency shift.

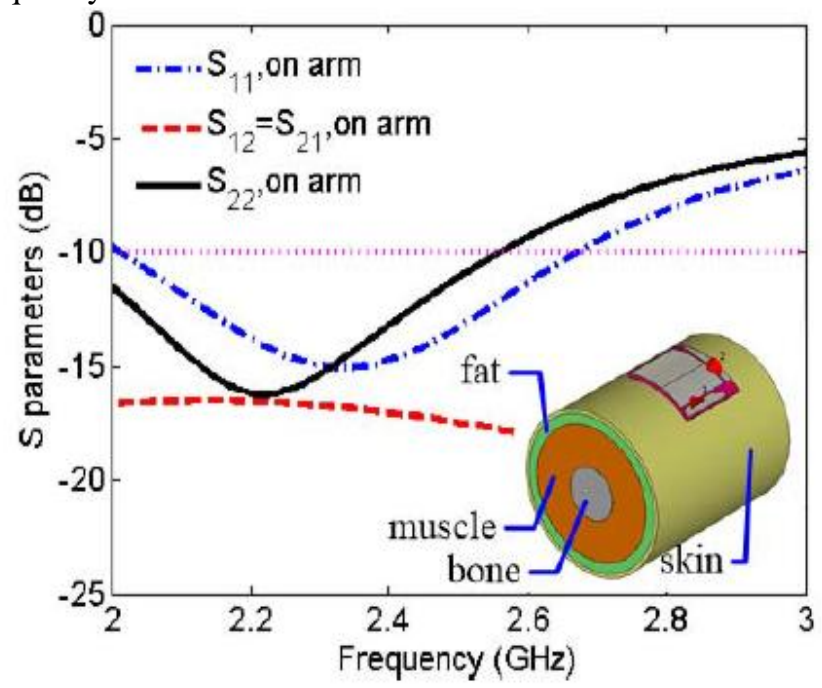

Fig 5. S-parameters for arm-loaded MIMO system [8] 
Table I: Material Properties Of Human Arm Model

\begin{tabular}{c|c|c|c|c}
\hline \hline & skin & fat & muscle & bone \\
\hline$\varepsilon_{r}$ & 37.95 & 5.27 & 52.67 & 18.49 \\
\hline Conductivity $(\mathrm{S} / \mathrm{m})$ & 1.49 & 0.11 & 1.77 & 0.82 \\
\hline Density $\left(\mathrm{kg} / \mathrm{m}^{3}\right)$ & 1001 & 900 & 1006 & 1008 \\
\hline \hline
\end{tabular}

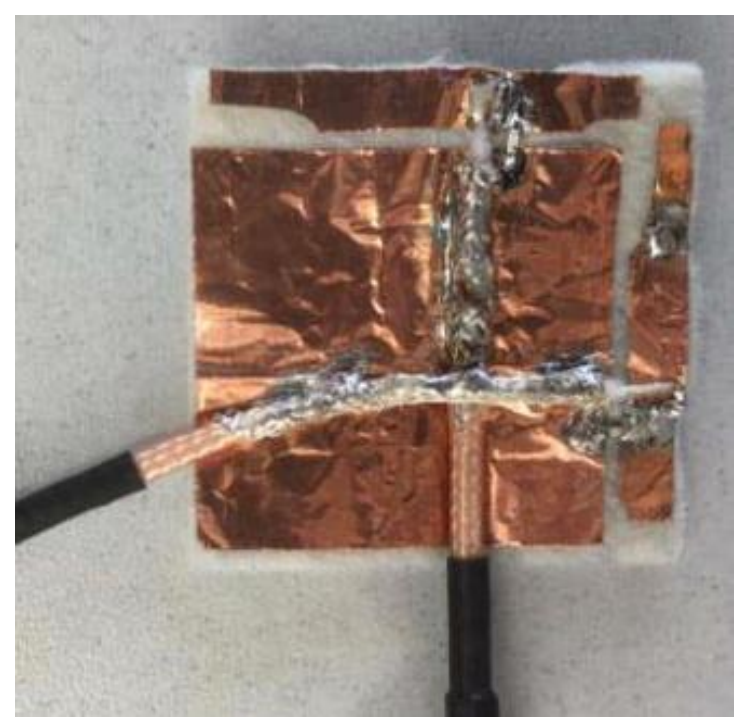

Fig 6. Fabricated prototype of the proposed MIMO antenna system for wearable applications

\section{WEARABLE TEXTILE ANTENNA WITH HUMAN BODY IMPACT AND SAR EVALUATION}

The patch antenna design at the GPS L1 band (1575.42 $\mathrm{MHz}$ ) and is implemented on a jeans textile substrate (dielectric constant $\mathrm{\varepsilon r}=1.7$, thickness $\mathrm{h}=1 \mathrm{~mm}$, loss tangent $\tan \delta=0.025$ ) [17].

In this paper, a homogeneous phantom has been considered in order to simulate the antenna performance impact and the SAR in the leg of an average human body (dielectric constant $\varepsilon r=42$, conductivity $\sigma=1 \mathrm{~S} / \mathrm{m}$ ). The impact of the human body on the antenna performance implies a detuning frequency of $1.6 \%$ and $G=1.2 \mathrm{dBi} ; \eta=$ $19 \%$ at the GPS operation frequency (Fig 5).

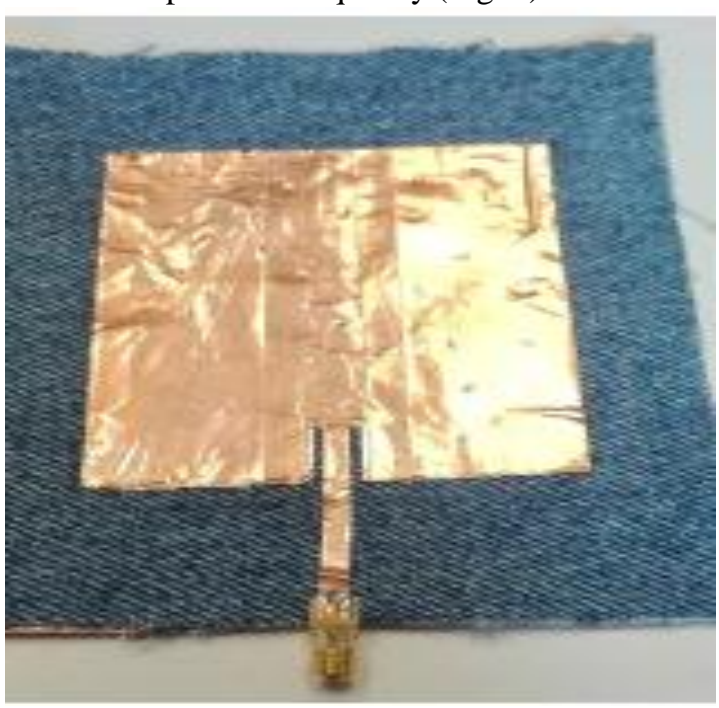

Fig 7. Wearable Textile Fabricated antenna

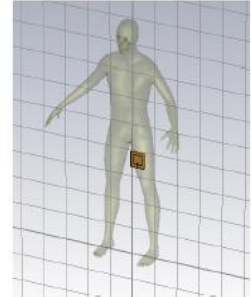

(a)

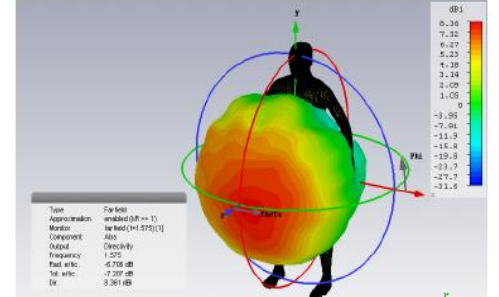

(b)

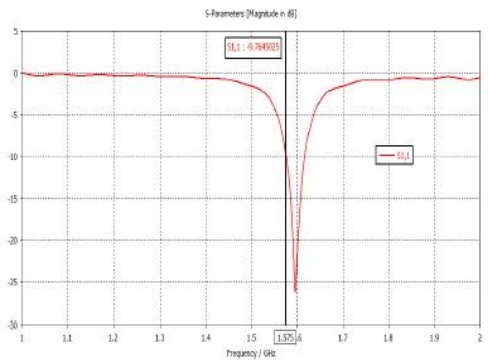

(c)

Fig 8. (a) Human Phantom model and wearable antenna location. (b) GPS radiation pattern including the human body impact. (c) On-body antenna patch return losses $S 11$

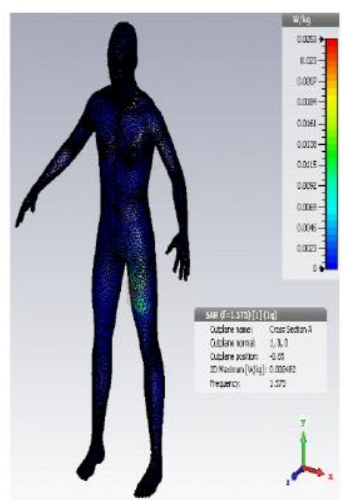

(a)

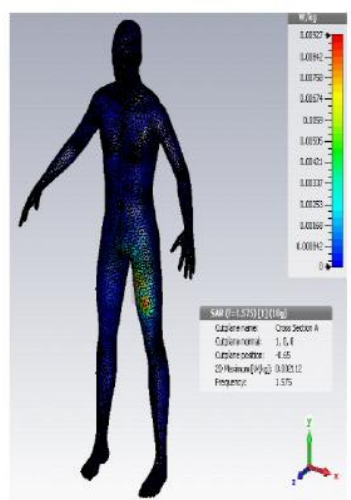

(b)
Fig 9. Simulated mass averaged SAR at GPS frequency: (a) $1 \mathrm{~g}$ and (b) $10 \mathrm{~g}$.

In this proposed work. the mass averaging SAR procedure is based on determining a point of averaged SAR calculation, searching for a $1 \mathrm{~g} / 10 \mathrm{~g}$ cube (iteratively) and integrating losses in the cube.

\section{SOME CHALLENGES AND CONSIDERATIONS\& RESULTS}

The patch antenna is a good candidate for wearable devices, since it is generally low profile and easy to fabricate. Using textile materials as substrates helps reduce surface wave losses and enhances the overall bandwidth. When a wearable textile antenna is worn on the human body, long term electromagnetic radiation poses potential health risks. Minimization of Specific Absorption Rate is therefore a challenge for wearable patch antennas.

The problems in the design of these structures, however, are the increasing overall antenna size and antenna fabrication complexity. Additionally, antenna performance

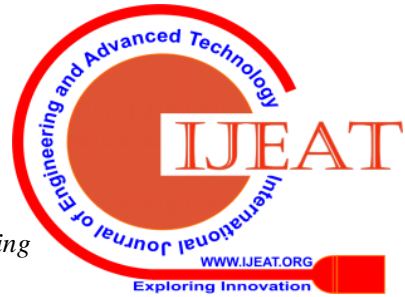


and robustness under deformations (bending, crumpling, wrinkling, and wetting) have to be investigated and incorporated into the design of wearable antennas to meet conformal requirements.

Table II: Comparison Of Performance Of Various Wearable Antennas Based On Previos Work

\begin{tabular}{|c|c|c|c|c|c|c|c|c|c|c|}
\hline 号瓷 & 杂 & 学 & 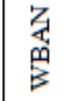 & 究 & 学 & 空 & 杂 & $\begin{array}{l}3 \\
3 \\
3\end{array}$ & 岑 & 学 \\
\hline 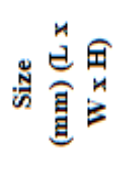 & 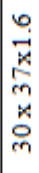 & 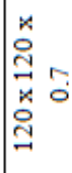 & \begin{tabular}{ll}
$x$ & \\
0 \\
$y$ & \\
$x$ & 0 \\
\cline { 1 - 1 } & 0 \\
0 & \\
0 &
\end{tabular} & 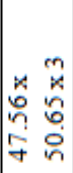 & 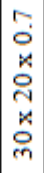 & $\begin{array}{l}r \\
0 \\
0 \\
x \\
\infty \\
c \\
x \\
0 \\
0\end{array}$ & $\begin{array}{l}2 \\
x \\
n \\
a \\
x \\
0 \\
0 \\
y\end{array}$ & \begin{tabular}{l}
$n$ \\
\hdashline \\
$x$ \\
0 \\
0 \\
$\vdots$ \\
0 \\
0
\end{tabular} & 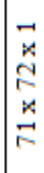 & 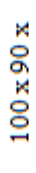 \\
\hline 罢 & 8 & 운 & 응 & 음 & 운 & $\stackrel{ }{\circ}$ & $\stackrel{ }{ }$ & 옥 & ? & $\stackrel{\overbrace{}}{\sim}$ \\
\hline 寻 嘼 & 곡 & ఫ。 & 우 & 0 & $\stackrel{\circ}{\mathrm{i}}$ & $\begin{array}{l}0 \\
\dot{m}\end{array} \mid$ & 乙 & $\stackrel{1}{\circ}$ & $\cong$ & 움 \\
\hline 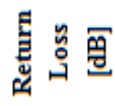 & $\begin{array}{l}\infty \\
\text { y } \\
n \\
7\end{array}$ & ตุ & $\frac{\pi}{7}$ & กุ & $\begin{array}{c}n \\
? \\
n \\
? \\
?\end{array}$ & $\begin{array}{l}c \\
⿱ \\
\infty \\
\infty \\
1\end{array}$ & m & 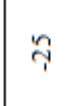 & 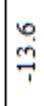 & $\stackrel{m}{\stackrel{n}{c}}$ \\
\hline 亗哭 & \begin{tabular}{l}
\multirow{2}{0}{} \\
0 \\
0
\end{tabular} & 1 & $\begin{array}{l}1 \\
\infty \\
0 \\
0 \\
0\end{array}$ & $\overrightarrow{0}$ & & 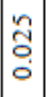 & ' & $\begin{array}{l}8 \\
8 \\
8 \\
0\end{array}$ & 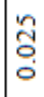 & '̂ \\
\hline 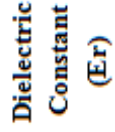 & r & $\stackrel{0}{-}$ & $\stackrel{\infty}{\sim}$ & $\underset{\rightarrow}{\stackrel{+}{*}}$ & 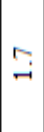 & $\begin{array}{l}y \\
\text { n }\end{array}$ & $\stackrel{4}{-1}$ & તุ & $\cong$ & $\cong$ \\
\hline 丞 & 离 & 点允 & 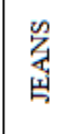 & 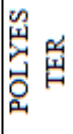 & 帘 & \begin{tabular}{|l} 
岁 \\
岀 \\
届 \\
\end{tabular} & 点 & 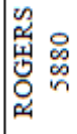 & 资 & 驾 \\
\hline 罢罩 & $\stackrel{\Delta}{\Delta}$ & $\stackrel{\nabla}{\Delta}$ & $\stackrel{\infty}{n}$ & $\stackrel{\nabla}{\mathrm{d}}$ & $\begin{array}{l}\Delta \\
\text { त }\end{array}$ & 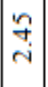 & 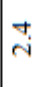 & $\stackrel{\nabla}{\Delta}$ & 告 & $\stackrel{\Delta}{\Delta}$ \\
\hline 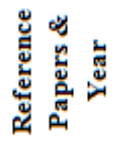 & $\begin{array}{l}\frac{\infty}{-} \\
\text { ㅇ } \\
\text { a }\end{array}$ & $\begin{array}{l}\infty \\
\stackrel{\infty}{\circ} \\
\text { 을 } \\
\text { 일 }\end{array}$ & 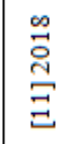 & 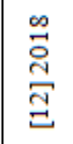 & 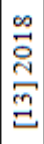 & 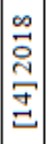 & 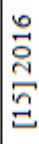 & 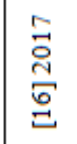 & 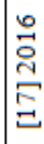 & $\begin{array}{l}0 \\
-1 \\
0 \\
\infty \\
=\end{array}$ \\
\hline
\end{tabular}

\section{CONCLUSION AND FUTURE SCOPE}

Recent research presented in these papers show that textile materials are preferred for wearable antennas as far as efficiency and flexibility is concerned. The fabricated wearable antennas are mainly planar microstrip patch antennas, because they mainly radiate perpendicularly to the planar structure and also their ground plane efficiently protects the human body. The bandwidth and efficiency performance of a planar microstrip antenna is mainly determined by the substrate dielectric constant and its thickness. Generally, textiles present a very low dielectric constant, between 1 and 2, as they are very porous materials and the presence of air approaches the relative permittivity to one. The surface wave losses within the substrates are reduced by low dielectric constant . Thereby increase the spatial waves and hence increases the impedance bandwidth of the antenna which results in increased resonance frequency of the antenna, allowing the development of antennas with acceptable efficiency and high gain. Also the thickness of the dielectric material in the designing antennas may be chosen to maximize the bandwidth of the planar antenna. However, this value may not optimize the antenna efficiency. Therefore, the choice of the thickness of the dielectric material is a compromise between efficiency and bandwidth of the antenna. Moreover, the thickness of the substrate also influences the geometric sizing of the antenna. It is important to design an optimized wearable antenna, balancing the trade-off between antenna's performance, its size and the complexity for the continuous improvement of WBAN applications. Conventional techniques for the designing and characterization of antenna should be modified by improving some parameters which are the major issues concerned with wearable antenna. The most common issue is the absorption of radiation by human body due to the proximity with the antenna. So the SAR value should be reduced as much as possible. Some other issues with such antennas are performance under wet conditions, environmental effects, dielectric properties, radiation characteristics near human tissue, bending conditions etc. Hence, all these issues have to be sorted out for designing an efficient and reliable wearable antenna.

\section{REFERENCES}

1. M. Patel and J. Wang, "Applications, challenges, and prospective in emerging body area networking technologies," IEEE Trans. Wireless Commun., vol. 17, no. 1, Feb. 2010. pp. 80-88,

2. P. Salonen, Y. Rahmat-Samii, \& M. Kivikoski. "Wearable antennas in the vicinity of human body" in Antennas and Propagation Society International Symposium, 2004. IEEE, vol. 1, pp. 467-470, IEEE, 2004.

3. S. Zhu \& R. Langley "Dual-band wearable antennas over EBG substrate". Electronics Letters, vol. 43, no. 3, pp. $141-142,2007$

4. F.-X. Liu, T. Kaufmann, Z. Xu, \& C. Fumeaux. "Wearable applications of quarter-wave patch and halfmode cavity antennas "IEEE Antennas and Wireless Propagation Letters, vol. 14, pp. 1478-1481, 2015.

5. Y. Liu, A. Levitt, C. Kara, C. Sahin, G. Dion, \& K. R. Dandekar. "An improved design of wearable strain sensor based on knitted RFID technology" in Antenna Measurements \& Applications (CAMA), 2016 IEEE Conference on, pp. 1-4, IEEE, 2016.

6. M. Seyedi, B. Kibret, D. T. Lai, \& M. Faulkner "A survey on Intrabody communications for body area network applications" IEEE Transactions on Biomedical Engineering, vol. 60, no. 8, pp. 2067-2079, 2013.

7. D. Wang, M. Ghosh, \& D. Smith. "Medical body area network (MBAN) with key-based control of spectrum usage.”Mar. 21 2017. US Patent 9,603,024

8. H. Li , S. Sun, B. Wang, and F. Wu. "Design of Compact Single-Layer Textile MIMO Antenna for Wearable Applications." IEEE TRANSACTIONS ON ANTENNAS AND PROPAGATION, VOL. 66, NO. 6, JUNE 2018.

9. Zaini, SR Mohd, and KN Abdul Rani. "Wearable InsetFed FR4 Microstrip Patch Antenna Design." IOP Conference Series: Materials Science and Engineering. Vol. 318. No. 1. IOP Publishing, 2018.

10. S. K. Jain, N. Baviskar, N. Golait, and S. Jain, "Design of 
Wearable Antenna for Various Applications," Antenna Test \& Measurement Society (ATMS India-18), pp. 2-6, 2018.

11. M. I. Ahmed, M. F. Ahmed, and A. A. Shaalan, "Novel Electrotextile Patch Antenna on Jeans Substrate for Wearable Applications," Progress in Electromagnetics Research C. 2018, Vol. 83, p255-265. 11p.

12. PriyeshJaiswal and Dr. PoonamSinha, "Design of Wearable Textile Based Microstrip Patch antenna for Bandwidth Enhancement," International Journal of Applied Engineering Research ISSN 0973-4562 Volume 13, Number 18 (2018) pp. 13647-13651.

13. Adel Y.I. Ashyap, Z. Z. Abidin, "Inverted E-Shaped Wearable Textile Antenna for Medical Applications," IEEE Trans. Antennas Propag, Volume 6,2018.

14. M. Annakamatchi, V. Keralshalini, "Design Of Spiral Shaped Patch Antenna For Bio-Medical Applications," International Journal of Pure and Applied Mathematics, Volume 118 No. 11 2018, 131-135.

15. B. Hu, G.-P. Gao, L.-L. He, X.-D. Cong, and J.-N. Zhao, "Bending andon-arm effects on a wearable antenna for $2.45 \mathrm{GHz}$ body area network,"IEEE Antennas Wireless Propag. Lett., vol. 15, pp. 378-381, 2016.

16. X. Hu, Y. Sen, and V. A. E. Guy, "Wearable button antenna for dual-band WLAN applications with combined on and off-body radiation patterns,"'IEEE Trans. Antennas Propag., vol. 65, no. 3, pp. 1384-1387, Mar. 2017.

17. I. Gil and R. Fern'andez-Garc'ia, "Wearable GPS Patch Antenna on Jeans Fabric," 2016 Progress In Electromagnetic Research Symposium (PIERS), Shanghai, China, 8-11 August.

18. G. Christina, A. Rajeswari, M. Lavanya, J. Keerthana, K. Ilamathi, and V. Manoranjitha, "Design and development of wearable antennas for telemedicine applications," 2016 International Conference on Communication and Signal Processing (ICCSP), Melmaruvathur, 2016, pp. 2033-2037. 